\title{
Influência da concentração de ácidos no processo de extração \\ e na qualidade de pectina de bagaço de maçã
}

\author{
Influence of acid concentration on extraction \\ and quality of apple pomace pectin
}

\author{
Heloísa Cristina Ramos Fertonani ${ }^{1}$; Ardalla Scabio²; Maria Helene Canteri \\ Schemin ${ }^{3}$; \\ Eliana Beleski Borba Carneiro ${ }^{4}$; Alessandro Nogueira ${ }^{5}$ Gilvan Wosiacki ${ }^{6 *}$
}

\section{Resumo}

\begin{abstract}
No processamento do suco concentrado de maçã, o bagaço residual da primeira extração é reidratado e prensado novamente a fim de aumentar o rendimento, tornando-se então a matéria-prima para a obtenção industrial de pectina. Neste trabalho os objetivos compreenderam estabelecer os protocolos de beneficiamento do bagaço e de uso de ácidos minerais e orgânicos no rendimento gravimétrico, usando o grau de esterificação, medido por técnicas espectrofotométricas e titulométricas como referencial de qualidade. A farinha de bagaço de maçã, com umidade de $12 \%$ apresentava $33,4 \%$ de açúcares redutores, e $40 \%$ de fibra alimentar e $10-15 \%$ de pectina, em base seca, com coloração própria. Os parâmetros do processo de extração das substâncias pécticas, $97^{\circ} \mathrm{C} / 10$ minutos e proporção soluto: solvente 1:40 permitiram estabelecer a eficiência de cada ácido na concentração de 1 a $750 \mathrm{mMol} / \mathrm{L}$ na solubilização da protopectina. Foram diferenciados dois tipos de comportamentos dos agentes ácidos: [1] liberação de pectina em baixas concentrações e destruição em elevados teores e [2] rendimento gravimétrico crescente, atingindo valores superiores aos possíveis, indicando uma agregação de grupamentos orgânicos na estrutura. $\mathrm{O} \mathrm{HNO}_{3}$ foi considerado o mais indicado para a extração de pectina, em concentração máxima de $100 \mathrm{mMol} / \mathrm{L}$.
\end{abstract}

Palavras-chave: Resíduos agroindustriais, substâncias pécticas, extração, rendimento, qualidade

\begin{abstract}
In concentrated apple juice processing units the pomace is washed with tap water in order to increase the yield so that the industrial by-product contains no more soluble pectin but only insoluble protopectin. In this article the main objectives were to establish a procedure to prepare the apple pomace as raw material and to extract pectin with several kinds and concentration of mineral and organic acids considering its degree of esterification, determined by titrimetric and spectroscopic techniques, as quality references. Dried apple pomace, with $12 \%$ moisture, showed $33.4 \%$ reducing sugars and $40 \%$ dietary fiber in dry
\end{abstract}

1 Departamento de Engenharia de Alimentos da Universidade Estadual de Ponta Grossa (DEA/UEPG);

2 Bolsista de Apoio Técnico do CNPq (DEA/UEPG)

3 Universidade Tecnológica Federal do Paraná (UFTPR), Unidade de Ponta Grossa

4 Departamento de Química da UEPG

5 Bolsista de Prodoc/Fundação Capes

6 Bolsista de Produtividade em Pesquisa CNPq. Universidade Estadual de Ponta Grossa, Campus de Uvaranas, Departamento de Engenharia de Alimentos, Ponta Grossa, Paraná. E-mail: wosiacki@uol.com.br.

* Autor para correspondência 
weigth basis, with proper color. The extraction processing parameters $\left(97^{\circ} \mathrm{C} / 10 \mathrm{~min} /\right.$ solute: solvent ratio 1:40) of pectic substances allowed to establish the efficiency of each acid for protopectin solubilization, from 1 up to $750 \mathrm{mMol} / \mathrm{L}$. Two acidic mechanisms were clearly observed. [1] The first, pectin-releasing at low and pectin-degrading reactions at high concentrations and [2] the second, increasingly gravimetric yields reaching values higher than possible, suggesting an attachment of organic groups in the pectic structure. $\mathrm{HNO}_{3}$ was defined as the more interesting acid for pectin extraction.

Key words: Industrial by-products, economic values, extraction, yield, quality

\section{Introdução}

As maçãs industriais brasileiras, aquelas desqualificadas para a comercialização por não atenderem os padrões de qualidade quanto à forma, tamanho, distribuição de cor e presença de cicatrizes ou defeitos na epiderme, passam a suprir como matéria-prima as unidades processadoras de suco concentrado ou bebida fermentada (NOGUEIRA et al., 2005). O montante, em 2005, de 300 mil toneladas representando $30 \%$ da produção nacional, contem cerca de $1 / 3$ de baixa sanidade que devem ser descartadas face à contaminação visível por bolores e provável presença de patulina, que é degradada nos processos fermentativos (CELLI, 2006).

O principal subproduto do processamento da maçã, o bagaço, representa de 20 a 40\% da matériaprima em função do nível tecnológico adotado. Tratase de um material altamente instável do ponto de vista microbiológico, com elevado conteúdo de compostos fermentáveis, e seu descarte pode acarretar forte impacto ambiental. Entretanto, demonstra-se excelente para fins biotecnológicos, compreendendo a produção de etanol, aromas, gás natural, ácido cítrico, pectinas, enzimas e cogumelos, além de outros processos como extração de fibras e carvão vegetal (NOGUEIRA et al., 2005).

A constituição da polpa em termos analíticos da matéria-prima depende muito da metodologia empregada e assim, segundo Kennedy et al. (1999) compreende $94,5 \%$ de cascas e polpas, $4,4 \%$ de sementes e $1 \%$ da parte central. Em base fresca contém $80 \%$ de umidade, $14 \%$ de sólidos solúveis (glucose, frutose e sacarose, ácidos orgânicos), e de 11,6 a $44,5 \%$ de fibras, fração composta por 12 a $23,2 \%$ de celulose, 6,4 a $19 \%$ de lignina, 3,5 a $18 \%$ de pectina e 5 a $6,2 \%$ de hemiceluloses. Segundo
Cho e Hwang (2000), o bagaço de maçã contém $11,4 \%$ de proteína, $3,7 \%$ de lipídeos, $1,8 \%$ de cinzas e 70,9\% de carboidratos, fração constituída de 38,3\% de açúcares neutros, 27,4\% de ácido urônicos e 5,2\% de amido. De acordo com Endress (2000) e Schieber et al. (2003), o bagaço fresco de maçãs apresenta de 10 a $15 \%$ de pectina em base seca.

Algumas revisões têm sido publicadas descrevendo estrutura, processamento e aplicações de pectinas (KERTESZ, 1951; PILNIK, 1990; MAY, 1990; ROLIN; DE VRIES, 1990; PEREZ; MAZEAU; PENHOAT, 2000; RIDLEY; O’NEILL; MOHNEN, 2001) e mais recentemente Willats, Knox e Mikkelsen (2006) ressaltaram recentes avanços na estrutura discutindo as conseqüências para produção e aplicações. A pectina é descrita como uma família de oligossacarídeos e polissacarídeos com algumas estruturas comuns mas bastante diversas no que diz respeito a estrutura fina.

O bagaço industrial é lavado no processo visando a extração maximizada de compostos solúveis em água e assim a pectina encontra-se em sua forma insolúvel, como protopectina, ainda ligada à estrutura da parede celular da fruta. Para a extração de pectina, o bagaço seco é tratado com ácidos minerais diluídos a temperaturas elevadas para solubilizar a protopectina. Entretanto, no processo, ocorrem também reações de hidrólise do produto, razão pela qual as condições de processamento devem ser cuidadosamente programadas a fim de maximizar um evento e minimizar o outro.

Neste trabalho, os objetivos foram identificar o comportamento de ácidos minerais e orgânicos em diferentes concentrações sobre o processo de extração de pectina de bagaço de maçã e influência sobre as características titulométricas, em especial 
o seu grau de esterificação visando estabelecer o ácido e as condições mais adequadas para o processamento.

\section{Material e Métodos}

\section{Material}

Maçãs comerciais da variedade Joaquina foram cedidas pela Estação Experimental de São Joaquim (Epagri/SC), amostras de pectinas comerciais de maçã de alta (HMP) e baixa metoxilação (LMP), pelo fabricante Herbstreith \& Fox e as enzimas pectinolíticas comerciais Pectinex 3XL (Novozymes do Brasil), pelo representante oficial da LNF no Brasil (Bento Gonçalves/ RS).

\section{Métodos}

\section{Beneficiamento do bagaço}

As maçãs foram selecionadas, higienizadas e fragmentadas em processador semi-industrial (Processing Metvisa, Type MPA). A massa ralada foi acondicionada em telas de polietileno superpostas entre placas de madeira revestidas e prensada a 3 $\mathrm{kgf} / \mathrm{cm}^{2}$ em equipamento hidráulico (Hydraulica Press Eureka, Senger) para extração do suco e obtenção do bagaço. O subproduto foi lavado com água à razão de $1: 2(\mathrm{~m} / \mathrm{v})$ à temperatura ambiente por 30 minutos (MINKOV; MINCHEV; PAEV, 1996), centrifugado, desidratado em estufa de circulação de ar (TE-394, Tecnal) à temperatura de $25^{\circ} \mathrm{C}$ e posteriormente a $60^{\circ} \mathrm{C}$, overnight. Em seguida, foi fragmentado em moinho tipo Cróton, tamisado e recolhida a fração que fica retida em $60 \mathrm{MESH}$, e armazenada a temperatura ambiente em pacotes plásticos.

\section{Extração ácida}

Em um balão de fundo redondo contendo bagaço de maçã numa razão de 1:40 $(5 \mathrm{~g} / 200 \mathrm{~mL})$ foi colocado em uma manta aquecedora e adaptado a um condensador. Simultaneamente foram preparados
200 mL de uma solução de ácido em dupla concentração à prescrita para o ensaio. Ambos os frascos foram colocados para aquecer e quando atingiam a temperatura de ebulição, a solução ácida era colocada na suspensão contendo o bagaço a ser hidrolisado, e deixado em ebulição por 10 minutos. Ao final deste tempo, o sistema foi resfriado em banho de gelo (SCHEMIN, 2003).

\section{Precipitação alcoólica de pectinas}

A suspensão contendo as pectinas solúveis em ácido foi adicionada por gotejamento em um copo de vidro contendo álcool absoluto, sob agitação constante até que a relação álcool: hidrolisado fosse 2: 1 e então o sistema foi deixado em repouso por 30 minutos. Os compostos floculados ou precipitados foram retirados por filtração em cheese cloth e após remoção de substâncias solúveis em álcool com 200 $\mathrm{mL}$ a $66 \%$, o resíduo foi desidratado por prensagem manual contra papel de filtro e após, por evaporação à temperatura ambiente em estufa com fluxo de ar forçado. O material seco foi fragmentado manualmente em graal de vidro e armazenado em frascos plásticos em dessecador. Para serem analisadas, as frações obtidas foram previamente mantidas em atmosfera de pentóxido de fósforo durante, no mínimo, 24 horas (SCHEMIN, 2003).

\section{Análises}

$\mathrm{Na}$ determinação do rendimento, o bagaço seco foi moído e tamisado a $60 \mathrm{MESH}$, sendo calculado o rendimento gravimétrico como a razão do produto pela matéria-prima seca.

As amostras de pectinas foram qualificadas quimicamente por titulometria considerando-se a determinação de quantidades de carboxilas livres, esterificadas e os teores relativos de polissacarídeos ácidos e fração de açúcares neutros. Cerca de 250 $\mathrm{mg}$ de pectina foram umedecidas com $2 \mathrm{ml}$ de álcool e dissolvidas em $25 \mathrm{~mL}$ de água deionizada sob 
agitação constante por 30 minutos com agitador magnético, com determinação do $\mathrm{pH}$ da solução. Por adição de $\mathrm{NaOH} 0,1 \mathrm{~N}$, as carboxilas livres dos ácidos anidrogalacturônicos foram eram neutralizadas, bem como as carboxilas esterificadas, após saponificação, com $10 \mathrm{~mL} \mathrm{NaOH} 0,25 \mathrm{~N}$ por 30 minutos a temperatura ambiente $\left(25^{\circ} \mathrm{C}\right)$ e neutralização com
$10 \mathrm{~mL} \mathrm{HCl} \mathrm{0,25} \mathrm{N,} \mathrm{obtendo-se} \mathrm{assim} \mathrm{os} \mathrm{valores} \mathrm{de}$ $\mathrm{mEq}$ de $\mathrm{NaOH}$ referentes aos dois tipos, livres e esterificados, respectivamente representados por mEq' e mEq" (WANG; PAGAN; SHI, 2002; WOSIACKI et al., 1977). Com os dados obtidos foram feitos os cálculos segundo as fórmulas:

\section{Quantidade de massa por mEquivalentes}

Teor de resíduos de ácido galacturônico

Teor de metoxila

Percentual de ácido poligalacturônico

Percentual de açúcares neutros

Grau de esterificação

Grau de esterificação

(fórmula alternativa

Proporção de teor de resíduos de ácido galacturônico e de metoxilas

$$
Z=\frac{\text { massa }}{m \text { Eqtotais }}
$$

$$
A U A \%=\frac{17600}{Z}
$$

$$
M e O \%=\frac{\left(m E q^{\prime \prime} * 31 * 100\right)}{m a s s a}
$$

$$
\text { Fração ácida }=\text { AUA\% } \%+M e O \%
$$

Fração neutra=100 -fração ácida

$$
D E=\left(\frac{176}{31}\right) *\left(\frac{M e O}{A U A}\right)
$$

$$
D E=\frac{m E q^{\prime \prime}}{\left(m E q^{\prime}+m E q^{\prime \prime}\right)}
$$

$84 \% A U A=16 \% M E O=100 \% D E$
$\mathrm{Na}$ análise de espectroscopia no infravermelho por transformadas de Fourier (FTIR) foram utilizadas pastilhas de $\mathrm{KBr}$ contendo $2 \mathrm{mg}$ de amostras desidratadas de pectinas obtidas por prensagem (50N/sq.in) e analisadas em espectrofotômetro Shimadzu 8400 FT-IR com $4 \mathrm{~cm}^{-1}$ de resolução, com espectros registrados na faixa de 4000 a $500 \mathrm{~cm}^{-1}$. O cálculo dos graus de esterificação foi feito considerando a razão entre a área relativa à banda $1740 \mathrm{~cm}^{-1}$ (grupos carboxílicos esterificados) e as áreas relativas às bandas $1740 \mathrm{~cm}^{-1} \mathrm{e} 1620 \mathrm{~cm}^{-1}$ (esterificados e livres), respectivamente (MARCON et al., 2005).
Os açúcares redutores redutores totais foram quantificados pelo método químico clássico (SOMOGYI, 1945; NELSON, 1944). A glucose foi quantificada pelo método enzimático da glucoseoxidase, sendo a sacarose e a frutose calculadas por diferença. Todos os carboidratos foram expressos como monossacarídeos em g/100mL. A acidez titulável total foi determinada por titulometria com $\mathrm{NaOH} 0,1 \mathrm{Mol} / \mathrm{L}$ em $\mathrm{pH}$ 8,33, calculada como ácido málico e expressa em g/100 $\mathrm{mL}$. Todas as análises foram feitas por métodos oficiais (INSTITUTO ADOLFO LUTZ, 1985; TANNER; BRUNNER, 1985). 
A análise de microscopia eletrônica foi realizada por técnica de varredura (SEM) em duas amostras de pectina da fração experimental correspondente ao processo com parâmetros definidos $(100 \mathrm{mMol} /$ L; $10 \mathrm{~min}$ ), sendo que uma foi finamente fragmentada enquanto que a outra permaneceu como película irregular e translúcida. As amostras foram fixadas em suportes metálicos e receberam por vaporização (SHIMADZU IC50) uma fina camada de ouro para leitura com detector de elétrons (SHIMADZU SSX 550).

\section{Efeito do tipo e da concentração de ácido}

A solubilização de substâncias pécticas foi feita em água a uma proporção de 1:40 tendo sido usados os ácidos minerais $\mathrm{HNO}_{3}$ e $\mathrm{HCl}$, e os orgânicos succínico, lático, tricloroacético, cítrico e málico, às concentrações finais de 1, 5, 10, 25, 50, 100, 250, 500 e $750 \mathrm{mMol} / \mathrm{L}$. A temperatura de reação foi de $97^{\circ}$ $\mathrm{C}$ e o tempo de 10 minutos.

\section{Efeito do $\mathrm{HNO}_{3}$ a baixas concentrações}

Foram feitos ensaios de extração de pectina de farinha de bagaço de maçã com ácido nítrico com ênfase na faixa de 1 a $100 \mathrm{mMol} / \mathrm{L}$, levando em consideração as possibilidades de ampliação do sistema e as características da massa em processamento.

\section{Resultados e Discussão}

No processo de desidratação do bagaço de maçã

O beneficiamento do bagaço de maçã foi feito em duas etapas: extração dos compostos solúveis em água - o que inclui pectinas - até $2^{\circ}$ BRIX residuais (NOGUEIRA et al., 2005) e desidratação por processo térmico $60^{\circ} \mathrm{C}$ em estufa de ar forçado. Dessa forma, foi obtido o modelo de perda de massa, demonstrado graficamente na Figura 1. O gráfico obtido indicou $\mathrm{R}^{2}=0,9972$, com um tempo de $1 / 2$ vida de 4:00 horas e uma estabilização em 10 horas (Figura 1).

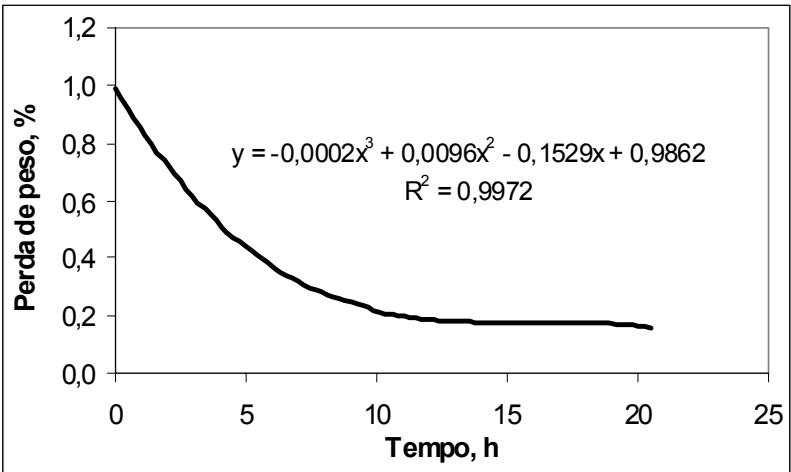

Figura 1. Isoterma de dessorção de umidade de bagaço de maçã a $60^{\circ} \mathrm{C}$ em estufa de circulação de ar.

Estudos sobre a desidratação de bagaço por processos térmicos têm demonstrado resultados mais rápidos com equipamentos industriais, evidenciando condições mais brandas, de $60^{\circ} \mathrm{C}$, com $\mathrm{t}_{1 / 2}$ de 2 horas, ao contrário dos obtidos com temperaturas de 70 a $105^{\circ} \mathrm{C}$, com um $\mathrm{t}_{1 / 21}$ de 1 a $1: 15 \mathrm{~h}$, embora a estabilização do processo também ocorra após 10 horas (COSTENLA; PONCE; LOZANO, 2002). Os autores discriminam os dois conjuntos pelas constantes de dessorção, significativamente diferentes entre si e confirmam que cinética da desidratação seguiu um modelo de $1^{\mathrm{a}}$ ordem, explicitado pela equação: $\mathrm{X} / \mathrm{Xo}=\exp (-k t)$.

\section{O bagaço desidratado de maçã}

A fração com partículas inferiores a $80 \mathrm{MESH}$ do bagaço desidratado, moído e tamisado constituiuse no material para os experimentos. Trata-se de um material higroscópico, com coloração que revela a presença de compostos fenólicos oxidados ligados à estrutura de substâncias pécticas (SCHIEBER et al., 2003). O clareamento com peróxidos alcalinos causa prejuízo a estas propriedades face à despolimerização e desmetoxilação das substâncias pécticas (RENARD; THIBAULT, 1996). Na tabela 1 são apresentados os resultados das análises físicoquímicas do bagaço da variedade Joaquina. 
Tabela 1. Características físico-químicas do bagaço de maçã cultivar Joaquina.

\begin{tabular}{cllllllc}
\hline $\begin{array}{c}\text { Amostra de } \\
\text { bagaço }\end{array}$ & Umidade & Cinzas & Proteína & Lipídios & Açúcares & Acidez & Fibras \\
\hline & 11,94 & 1,51 & 3,88 & 2,82 & 29,43 & 1,00 & 36,00 \\
Úmida & 1,72 & 4,41 & 3,20 & 33,44 & 1,14 & 40,91 \\
Seca & 0 & 8 &
\end{tabular}

Cada bagaço apresenta composição química dependente do processo de obtenção (tipo de moagem e processo de extração dos sólidos solúveis) e de beneficiamento (tempo e temperatura de desidratação). Em termos de umidade, o valor encontrado de $6,30 \mathrm{~g} / 100 \mathrm{~g}$ confere ao produto boa estabilidade físico-química, com um tempo de conservação longo desde que armazenado adequadamente. O teor de cinzas de $1,80 \mathrm{~g} / 100 \mathrm{~g}$ está compatível aos citados por Hwang (1993) e por Marcon et al. (2005) e se refere aos minerais retidos no bagaço, não lixiviados no processo de reidratação e prensagem. O teor de proteína de $3,88 \mathrm{~g} / 100 \mathrm{~g}$ está mais compatível com os resultados de Hwang (1993) do que com os de Marcon et al. (2005) embora tenha tido o mesmo tipo de processamento e procedimentos de análise. Entretanto, o teor de lipídeos, de 3,7 g/ $100 \mathrm{~g}$, está entre os valores relatados por estes autores. O teor de açúcares totais $(41,18 \mathrm{~g} / 100 \mathrm{~g})$, retidos nos restos de paredes celulares e não extraídos com água, são elevados e superiores ao relato de Marcon et al. (2005) embora na literatura sejam encontrados valores da mesma magnitude, como 38,3 $\mathrm{g} / 100 \mathrm{~g}$ (HWANG, 1993) ) e bem mais baixos como 22,5 g/100 g (JOSHI; KAUSHAL, 1995). A acidez total titulável, superior à do suco despectinizado, é muito dependente das características genotípicas da variedade. O teor de fibra alimentar é elevado $(39 \mathrm{~g} /$ $100 \mathrm{~g}$ ) embora outros autores tenham encontrado valores menores, como 20 g/100 g (JOSHI; KAUSHAI, 1995).

É possível observar que as características de qualidade físico-química de bagaço de maçã são muito dependentes das operações de beneficiamento e dos métodos de análise empregados, além das diferenças varietais. Os resultados apresentados por Marcon (2005) referem-se à variedade Gala, e os de Joshi e Kaushal (1995) e Hwang (1993) à uma mistura de variedades industriais.

\section{O processo de extração ácida de pectina}

Como a hidrólise ácida que degrada a protopectina ocorre simultaneamente a várias outras reações, isso induz a aceitar que as pectinas estão sendo hidrolisadas (HWANG, 1993), em especial, a ligação éster existente em grupamentos carboxílicos de resíduos de ácidos anidrogalacturônicos. Assim, à medida que os polissacarídeos precipitáveis em álcool estão sendo extraídos, estão também sendo degradados ou desesterificados, levando à obtenção de pectinas de baixos pesos moleculares ou baixos graus de esterificação.

\section{Efeito de diferentes ácidos na extração de substâncias pécticas}

$\mathrm{Na}$ Tabela 2 estão apresentados os resultados, expressos como as substâncias precipitadas com etanol após solubilização ácida das protopectinas presentes em bagaço de maçã.

A observação destes resultados leva à constatação de que existem pelo menos dois mecanismos distintos, manifestados pela atuação de dois grupos de ácidos. O primeiro conjunto, que compreende os ácidos nítrico, clorídrico, succínico e lático, resulta num rendimento crescente até a concentração de $100 \mathrm{mMol} / \mathrm{L}$. Posteriormente, é mantida a quantidade extraída ou diminui, até a concentração de $750 \mathrm{mMol} / \mathrm{L}$, ou seja, há extração 
de pectinas com ácidos diluídos e degradação com ácidos concentrados. O segundo conjunto, representado pelos ácidos tricloroacético, cítrico e málico, apresenta rendimento crescente até valores que ultrapassam os teores de pectina citados na literatura para bagaço de maçã (ENDRESS, 2000;
SCHIEBER et al., 2003). Este comportamento é compatível para extração de pectinas com ácidos orgânicos diluídos e formação de moléculas maiores com incorporação de radicais ácidos esterificados às hidroxilas presentes nos açúcares neutros acompanhantes.

Tabela 2. Rendimento gravimétrico de substâncias pécticas do bagaço de maçã da variedade Joaquina, extraídas com ácidos minerais e orgânicos em concentrações de 1 a 750 mMol/L.

\begin{tabular}{|c|c|c|c|c|c|c|c|c|}
\hline \multirow{2}{*}{ Ácidos } & \multicolumn{8}{|c|}{ Substâncias precipitadas com etanol (g/100 g) } \\
\hline & [1] & [5] & [25] & [50] & [100] & [250] & [500] & [750] \\
\hline Nítrico & 1,00 & 2,10 & 16,09 & 18,63 & 19,26 & 16,39 & 15,95 & 14,26 \\
\hline Clorídrico & 1,53 & 1,65 & 11,45 & 13,74 & 16,00 & 20,23 & 17,19 & 13,67 \\
\hline Succínico & 0,80 & 1,60 & 2,29 & 3,56 & 6,44 & 7,00 & 3,47 & 2,70 \\
\hline Láctico & 0,69 & 0,90 & 0,99 & 1,49 & 4,03 & 4,15 & 4,33 & 4,32 \\
\hline Tricloroacético & 1,33 & 1,73 & 9,66 & 10,44 & 15,36 & 17,31 & 28,64 & 30,16 \\
\hline Málico & 1,25 & 2,27 & 3,30 & 4,91 & 5,62 & 10,47 & 16,52 & 19,41 \\
\hline Cítrico & 1,00 & 4,00 & 9,55 & 12,78 & 16,73 & 20,86 & 28,33 & 36,67 \\
\hline
\end{tabular}

Os dois mecanismos estão ilustrados na Figura 2. Evidencia-se que o limite de extração, da ordem de $20 \mathrm{~g} / 100 \mathrm{~g}$, é observado apenas para os ácidos minerais diluídos. Os ácidos orgânicos são bem menos eficientes, apesar de apresentarem um perfil semelhante quanto à diminuição do rendimento acima da concentração de 100 mMol/L (Figura 2A). Com o segundo conjunto de ácidos, todos orgânicos, o processo de extração aparentemente se prolonga até concentrações elevadas, como $750 \mathrm{mMol} / \mathrm{L}$, sem redução do rendimento, embora se saiba que os teores de pectina existentes no bagaço de maçã não são superiores a 20 g/100 g (Figura 2B).

Marcon et al. (2005), utilizando um planejamento experimental com os fatores tempo (20 - $80 \mathrm{~min}$.) e temperatura $\left(50-100^{\circ} \mathrm{C}\right)$, extraíram pectina de farinha de maçã da cv Gala com ácido cítrico, obtendo rendimentos de 5,7 a 16,8\%, Estes resultados foram compatíveis com os de Schemin (2003), que extraiu $20 \%$ de pectina de maçã com ácido cítrico a $100^{\circ} \mathrm{C}$ durante 110 minutos. Face ao encontrado neste trabalho (36\% de rendimento) observa-se que, aparentemente, a pectina extraída com altas concentrações de ácido cítrico à temperatura de ebulição deve conter também outros compostos ou pode ocorrer a ligação do ácido cítrico à estrutura péctica precipitável em etanol.

Ao serem analisados os resultados dos processos de extração com os mesmos ácidos na concentração máxima de $100 \mathrm{mMol} / \mathrm{L}$, observa-se que, no primeiro conjunto, a tendência da reação é logarítmica para os ácidos minerais e linear para os ácidos succínico e lático enquanto que, no segundo conjunto, a tendência é logarítmica para os três ácidos orgânicos testados (Figura 3). Na Figura 3 são apresentadas apenas as linhas de tendência dos dois conjuntos de ácidos, até $100 \mathrm{mMol} / \mathrm{L}$, possibilitando discriminar a eficiência dos diferentes ácidos no processo de extração de pectina. O melhor ácido considerado para o processo é o nítrico. Há similaridade no padrão de extração, embora não de produto, entre os ácidos clorídrico, tricloroacético e cítrico, visto que todos seguem tendência logarítmica, sendo o menos eficiente o ácido málico. O ácido lático e o succínico são absolutamente ineficientes no processo de extração de pectina e seguem uma tendência linear. 

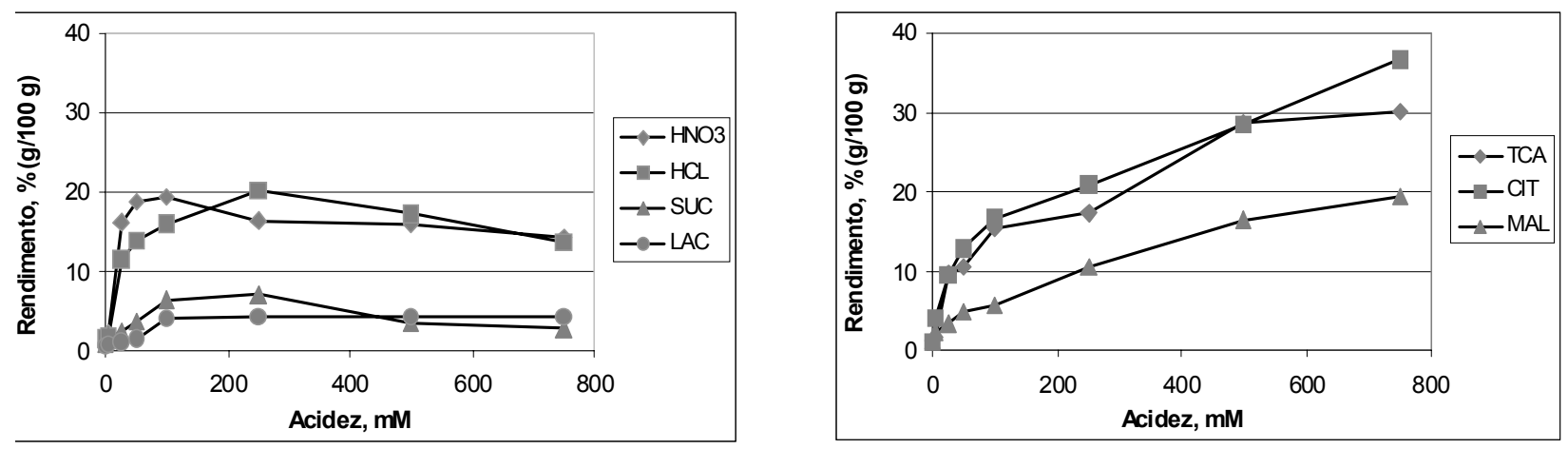

Figura 2. Rendimentos gravimétricos de obtenção de substâncias pécticas com os ácidos nítrico $\left(\mathrm{HNO}_{3}\right)$, clorídrico (HCl), succínico (SUC) e lático (LAC) (A) e com os ácidos tricloroacético (TCA), cítrico (CIT) e málico (MAL) (B), nas concentrações de 1 a $750 \mathrm{mMol} / \mathrm{L}$.
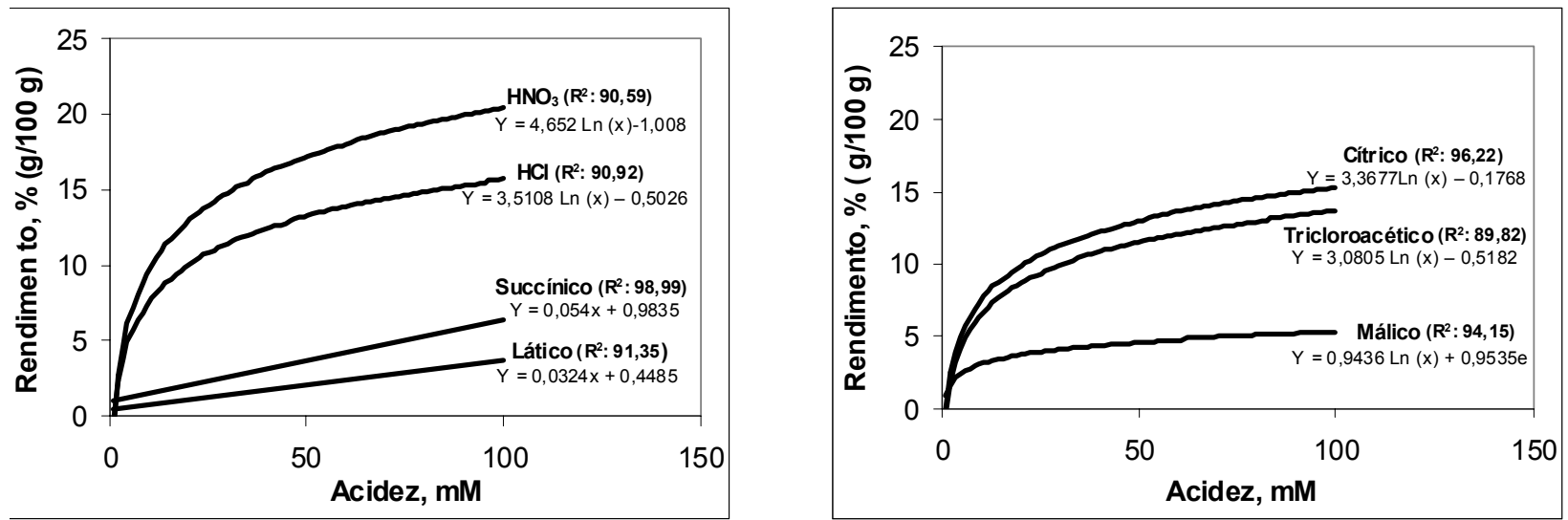

Figura 3. Curvas de tendência de rendimentos gravimétricos de obtenção de substâncias pécticas com os ácidos nítrico, clorídrico, succínico e lático (A) e com os ácidos tricloroacético, cítrico e málico (B), nas concentrações de 1 a $100 \mathrm{mMol} / \mathrm{L}$.

De uma forma simples as equações expressam os mesmos resultados apresentados anteriormente, demonstrando superioridade do ácido nítrico, semelhança aparente entre os ácidos clorídrico, cítrico, tricloroacético e succínico e baixa eficiência do ácido málico. Foram desconsiderados os coeficientes lineares das equações dos ácidos succínico e lático.

O sistema de extração com $\mathrm{HNO}_{3}(100 \mathrm{mMol} /$ L) por 10 min a temperatura de ebulição do solvente foi selecionado para direcionar os experimentos seguintes. Justifica-se essa escolha ao se levar em conta o comportamento de reação do ácido nítrico em condições diluídas, a partir da observação de que a concentração de $100 \mathrm{mMol} / \mathrm{L}$ representa um limite em termos do binômio extração: degradação.
Adicionalmente, considerou-se o poder de corrosão do ácido clorídrico e a incomum extração ou incorporação de outras substâncias às pectinas, com os ácidos tricloroacético e cítrico.

Os espectros de transmitância das pectinas, extraídas com os dois grupos de ácidos (Figura 4), quando elaborado na região do infravermelho (FTIR) de 400 a $4000 \mathrm{~cm}^{-1}$, fornecem muitas informações, pois compreendem faixa reconhecida como fingerprint de pectinas - 1300 a $800 \mathrm{~cm}^{-1}$ (GNANASAMBANDAM; PROCTOR, 2000; SINGHONG et al., 2004) bem como a dos polissacarídeos neutros - 1200 a $950 \mathrm{~cm}^{-1}$ (MANRIQUE; LAJOLO, 2002). A partir da superposição dos dois grupos é possível verificar a semelhança dos espectros, em especial na região de 
500 a $1500 \mathrm{~cm}^{-1}$, relacionada aos açúcares neutros. Essa região, por sua vez, é a mais sensível aos teores de ácidos do meio de reação, enfatizando um fato novo, a diferença de comportamento espectrofotométrico frente aos dois conjuntos de ácidos.

A observação dos espectros permite supor que se trate de pectinas com baixos valores de esterificação e que as modificações estruturais, principalmente aquelas relativas aos teores de açúcares neutros, já se encontrem alteradas antes mesmo de atingir valores elevados de ácidos. Desta forma aparentemente o aspecto tempo seja também importante como à temperatura a fim de se obter pectinas menos degradadas.

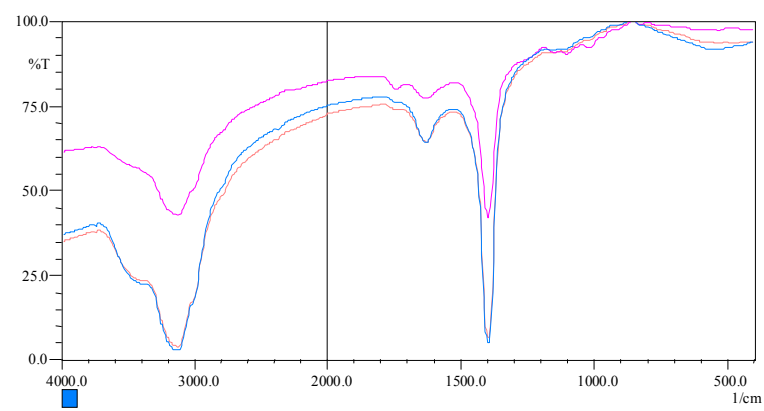

Figura 4. Espectros de pectinas extraídas com diferentes ácidos a $100 \mathrm{mMol} / \mathrm{L}$ durante 10 minutos a $100^{\circ} \mathrm{C}$. "A"HNO3, HCl, ácido succínico e ácido láctico. "B"- Ácido tricloroacético, cítrico e málico.

\section{Extração com ácido nítrico}

O sistema experimental de extração na razão 1:40 foi testado, com 5, 10 e 25 gramas de matéria-prima, a fim de verificar as influências de aumento de escala, ainda em bancada, sobre o rendimento gravimétrico das substâncias pécticas. A qualidade espectrofotométrica foi medida pelo cálculo do grau de esterificação subordinado às áreas dos picos relativos às carboxilas metoxiladas e livres, na região de 1500 a $2000 \mathrm{~cm}^{-1}$. A qualidade das substâncias pécticas já podia ser inferida no momento da extração ácida e da precipitação alcoólica, do ponto de vista prático de laboratório. Na tabela 3 são apresentados os resultados do ensaio de ampliação do sistema experimental, mostrando a influência do aumento de escala na extração de substâncias pécticas e no rendimento gravimétrico.

Com 5 g de matéria-prima, o rendimento foi de 16,09\% de substâncias pécticas. Em ensaios com maior quantidade de matéria-prima, os rendimentos foram levemente inferiores, refletindo as dificuldades práticas de homogeneização do material com maior massa e da necessidade de divisão em pequenas porções, aliadas à quantidade de álcool suficiente para a precipitação das substâncias pécticas. Quando se observa que existe um coeficiente de correlação de $99,78 \%$ na tendência linear de ampliação de escala com um modelo $\mathbf{y}=\mathbf{0 , 1 4 2 9 *}(\mathbf{x})$, conclui-se que as melhores condições para conduzir os experimentos estão vinculadas à praticidade no laboratório; ou seja, a partir de $25 \mathrm{~g}$ deve ser dividido em dois frascos, o que passa a ser complicado do ponto de vista da praxis laboratorial.

Tabela 3. Resultados quantitativos da ampliação do sistema em nível de bancada para extração de substâncias pécticas de bagaço de maçã.

\begin{tabular}{ccc}
\hline Matéria-prima, $(\mathrm{g})$ & Substâncias pécticas, $(\mathrm{g})$ & Rendimento, $(\%)$ \\
5,206 & 0,838 & 16,09 \\
10,006 & 1,418 & 14,17 \\
25,017 & 3,559 & 14,22 \\
\hline
\end{tabular}

\footnotetext{
* Temperatura de ebulição, razão soluto:solvente::1:40, 100 mMol/L de $\mathrm{HNO}_{3}$
} 


\section{Características de qualidade das substâncias pécticas}

A amostra de pectina experimental, extraída com $\mathrm{HNO}_{3} 100 \mathrm{mMol} / \mathrm{L}$ a $97^{\circ} \mathrm{C}$ por 10 minutos, foi comparada à amostras de pectinas comerciais de alta e baixa esterificação, em função das características titulométricas e espectrofotométricas na região do infra-vermelho - IR, e foi observada sob microscopia eletrônica por técnica de varredura (SEM).

\section{Qualidade titulométrica}

As características de qualidade compreendem os teores relativos de ácidos anidrogalacturônico (AUA) e metoxilas (MeO), cuja soma representa o percentual de ácido poligalacturônico. O percentual restante, até 100, indica o teor de açúcares neutros. O grau de esterificação independe da quantidade de massa, visto que a fórmula utilizada considera a razão entre a fração AUA metoxilada e a fração AUA total. Os resultados comparativos desses parâmetros estão apresentados na Tabela 4.

Tabela 4. Qualidade titulométrica das pectinas comerciais e experimental.

\begin{tabular}{lccccc}
\hline & AUA, \% & MEO, \% & $\begin{array}{c}\text { Fração ácida, } \\
\%\end{array}$ & $\begin{array}{c}\text { Fração } \\
\text { neutra, } \%\end{array}$ & DE , \% \\
\hline Experimental & $53,75 \pm 2,90$ & $4,81 \pm 0,81$ & $58,57 \pm 3,62$ & $41,43 \pm 3,62$ & $50,78 \pm 6,74$ \\
HMP- comercial & $61,41 \pm 0,42$ & $8,45 \pm 0,075$ & $69,83 \pm 0,49$ & $30,17 \pm 0,49$ & $75,7 \pm 0,17$ \\
LMP- comercial & $55,99 \pm 0,24$ & $5,02 \pm 0,035$ & $60,98 \pm 0,25$ & $39,02 \pm 0,25$ & $49,34 \pm 0,42$ \\
\hline
\end{tabular}

Observa-se existir semelhança maior com a amostra LMP comercial em todos os aspectos disponíveis. Entretanto, as três amostras são menos heterogêneas no teor de ácidos urônicos, sugerindo certa semelhança em termos de quantidade total.

\section{Qualidade espectrofotométrica}

Na Figura 5 estão apresentados os espectros no infravermelho das pectinas isoladas sob idênticas condições, com ampliação do sistema experimental, com as leituras em transmitância. Estes espectros correspondem ao fingerprint das pectinas com os picos nas freqüências em $1740 \mathrm{~cm}^{-1}$ e $1620 \mathrm{~cm}^{-1}$, relativos aos ácidos carboxílicos esterificados e não esterificados, respectivamente. Marcon et al. (2005) apresentaram os espectros IR de duas amostras padrões de pectinas de alto $(89 \%$ e $67 \%)$ e uma de baixo (22\%) grau de esterificação evidenciando as diferenças nas freqüências anteriormente citadas.
Determinou, inclusive, os graus de esterificação de pectinas isoladas seguindo um planejamento fatorial com repetições no ponto central, caracterizando pectinas de baixos teores de esterificação.

As determinações do grau de esterificação (DE) neste experimento foram feitas mediante software do equipamento Shimadzu e estão expressos em cada conjunto. A média dos valores do grau de esterificação encontrado, de 42,70 $\pm 0,81 \%$, está coerente com valor convencional de pectinas de baixos teores de esterificação (LMP), com espectros característicos. O baixo valor de desvio padrão entre as três amostras, extraídas da mesma forma, diferentes entre si em função de escala, revela um coeficiente de variação bastante pequeno $(<2,5 \%)$ indicando a estabilidade relativa das substâncias pécticas nas condições empregadas. 


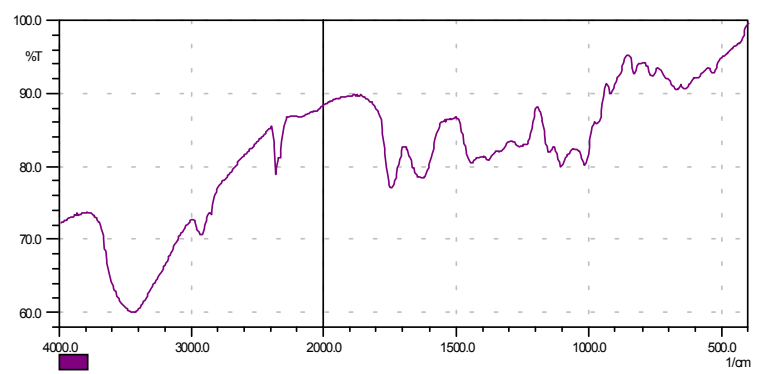

[1] Pectina experimental com grau de esterificação de $44 \%$

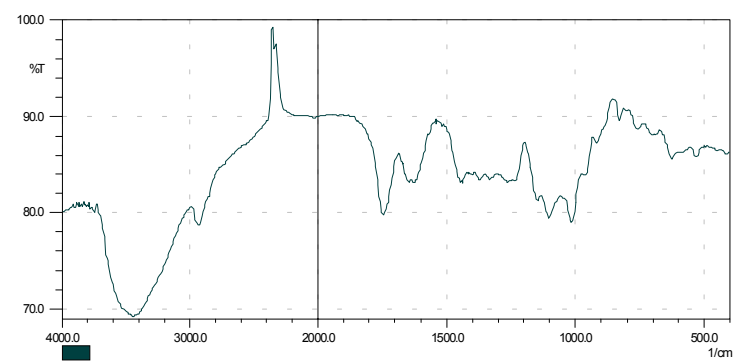

[2] Pectina comercial de alto grau de esterificação de $62 \%$

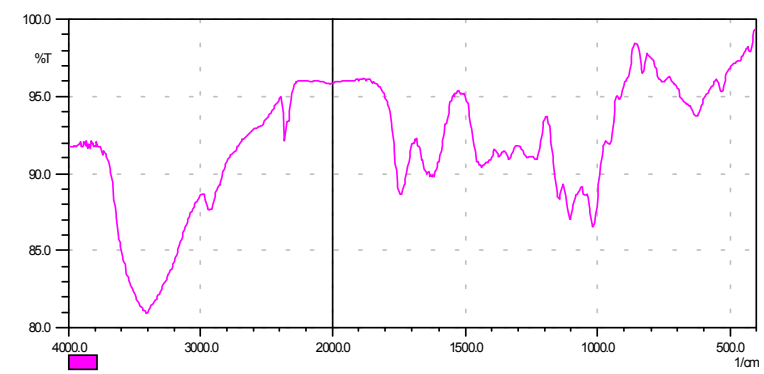

[3] Pectina comercial de baixo grau de esterificação de 49\%

Figura 5. Espectros de transmissão FT-IR de pectinas experimentais e comerciais.

Os espectros de compostos no IR das amostras comerciais e da experimental de pectina são apresentados na Figura 5. De acordo com a análise de componentes principais, nenhuma das três amostras analisadas apresentou grau acentuado de semelhança. Entretanto, os dados obtidos com as medidas das áreas dos picos referentes às carboxilas usados para o cálculo alternativo do grau de esterificação forneceram os valores deste parâmetro de qualidade péctica, indicado na legenda da figura, ou seja, $44 \%$ para a amostra experimental, $62 \%$ para a amostra comercial de HMP e 49\% para a de LMP. Estes cálculos, feitos com o aplicativo COREL PHOTO PAINT 12 forneceram valores ligeiramente inferiores aos obtidos por titulometria, mas ainda qualificam as pectinas comerciais como HMP ou LMP, e a experimental como LMP.

\section{Qualidade observada por eletromicrografia de varredura (SEM)}

A Figura 6 ilustra a pectina desidratada em pó e sob a forma de uma película. A pectina finamente pulverizada, homogênea a olho nu, em microscopia eletrônica de varredura com amplificação de $100 \mathrm{X}$ (Figura 6A), apresenta-se altamente heterogênea, com partículas multiformes e de diversos tamanhos, com aparência de fibras. Na realidade, o material é higroscópico e possibilita a formação de grumos de difícil solubilização posterior, de acordo com Thakur, Singh e Handa, (1997) o que pode ser o maior problema em nível industrial ou bancada, uma vez que impossibilita sua utilização ou mesmo sua caracterização. A Figura 6B ilustra, com ampliação de $200 \mathrm{X}$, a superfície de um filme de pectina antes da pulverização, mostrando um material aparentemente seco, mas com conteúdo de água ainda elevado, que demanda um agente desidratante forte, como pentóxido de fósforo. São visíveis estruturas de características fibrosas, ou pelo menos rugosas, conforme se observa na eletromicrografia. A superfície é rugosa e sensível ao tato. A própria umidade dos dedos faz com que ela se umedeça e se torne lisa favorecendo a junção com outras partículas de pectina e formando agregados cada vez maiores, se permanecer em ambiente com umidade relativa elevada. Por este motivo, a armazenagem da pectina foi em embalagem plástica ou de vidro fechada, 
contendo agentes dessecantes- sílica gel. Não foram encontrados na literatura especializada artigos relacionados à microscopia de varredura de pectinas especificamente, mas alguns se referem à parede celular, sugerindo a necessidade de averiguação da validade desta técnica ao estudo das características estruturais e morfológicas.

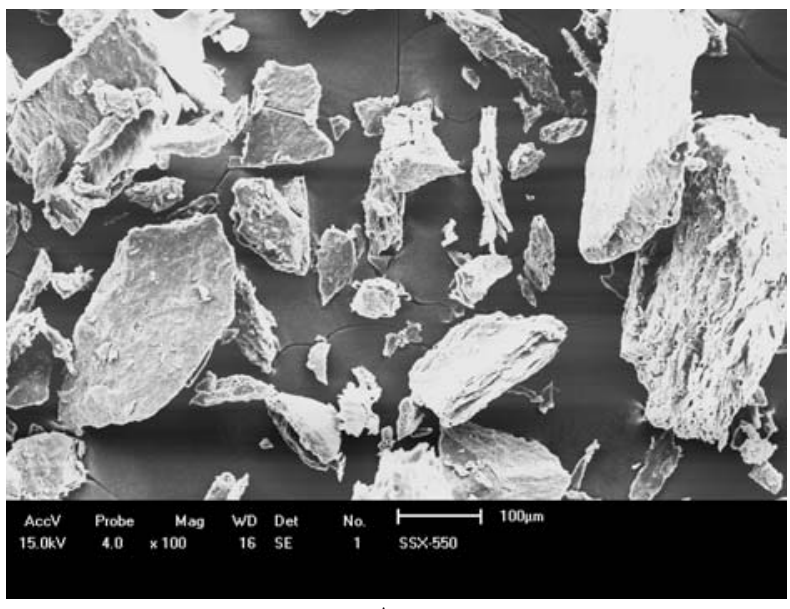

A

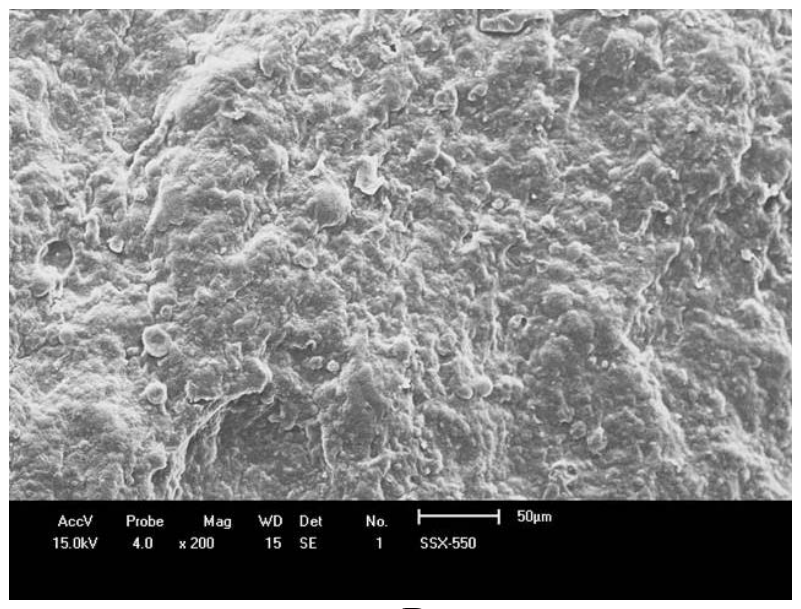

B

Figura 6. Microeletrografia de varredura de pectina em pó amplificada 100 vezes (A) e sob a forma de uma película desidratada com amplificação de 200 vezes (B).

\section{Conclusões}

A composição físico-química da farinha de bagaço de maçã, fortemente influenciada pelo tipo de processamento, apresentou $33 \%$ de açúcares redutores totais e $40 \%$ de fibras em base seca, incluindo as pectinas. $\mathrm{O}$ teor de umidade de $11 \%$ propicia um armazenamento em longo prazo, desde que mantida em frascos hermeticamente fechados. O processo de solubilização da protopectina de bagaço de maçã com concentrações de ácidos de 1 a $750 \mathrm{mMol} / \mathrm{L}\left(10 \mathrm{~min} / 97^{\circ} \mathrm{C} / 1: 40 \mathrm{~m} / \mathrm{v}\right)$ apresentou dois comportamentos distintos. Os ácidos nítrico, clorídrico, succínico e lático extraíram as substâncias pécticas, em baixas concentrações e em elevadas, apresentaram menor rendimento de extração, sugerindo degradação dos polímeros. Os ácidos cítrico, tricloroacético e málico em baixas concentrações extraíram as substâncias pécticas e em elevadas apresentaram maior rendimento gravimétrico, sugerindo agregação estrutural nos polímeros. Com os resultados foram estabelecidas as tendências de modelagem com maior expressão estatística a fim de determinar as melhores condições de trabalho em laboratório, com ênfase na faixa de 1 a $100 \mathrm{mMol} / \mathrm{L}$, ou seja, soluções ácidas diluídas. Com ácidos diluídos até $100 \mathrm{mMol} / \mathrm{L}$, o processo de extração segue tendência logarítmica com coeficientes de determinação superiores a $90 \%$, exceto para os ácidos succínico e lático, com tendência linear. Os coeficientes dos logaritmos indicam que os melhores agentes de solubilização das protopectinas são os ácidos nítrico, clorídrico, cítrico e tricloroacético, nesta ordem, tendência confirmada pelas extrações feitas com concentração $100 \mathrm{mMol} /$ L durante 10 minutos, numa razão $1: 40$ a $97^{\circ} \mathrm{C}$. O ácido nítrico apresentou os melhores resultados em termos de rendimento gravimétrico chegando ao nível de $20 \mathrm{~g} / 100 \mathrm{~g}$, justificando seu emprego em âmbito experimental. Os ensaios de ampliação do sistema de $5 \mathrm{~g}$ até $25 \mathrm{~g}$ de matéria-prima, sob as mesmas condições ainda em nível de bancada, identificaram um comportamento linear no rendimento, com coeficiente de correlação de 99,78\%. 


\section{Agradecimentos}

Os autores são profundamente agradecidos à UEPG por proporcionar as condições de trabalho em laboratório, ao $\mathrm{CNPq}$ pelas bolsas concedidas, à Epagri e à Herbstreith pelas amostras de produtos específicos.

\section{Referências}

CELLI, M. G. Patulina em maçãs e em produtos derivados: aspectos sanitários e controle empregando Saccharomyces cerevisiae. 2006.Dissertação ( Mestrado em Ciência e Tecnologia de Alimentos) - Universidade Estadual de Ponta Grossa, Ponta Grossa.

CHO, Y. J.; HWANG, J. K. Modeling the yield and intrinsic viscosity of pectin in acidic solubilization of apple pomace. Journal of Food Engineering, Essex, Inglaterra, v.44, n.2, p.85-89, 2000.

CONSTENLA, D.; PONCE, A. G.; LOZANO, J. E. Effect of pomace drying on apple pectin. Lebensmittel .Wisssenschaft und Technologie, Amsterdam, v.35, n.3, p.216-221, 2002.

ENDRESS, H. U. High quality resulting from product integrated environment protection-PIUS. Fruit Processing, Schonborn, v.10, p.273-276, 2000.

GNANASAMBANDAM, R.; PROCTOR, A. Determination of pectin degree of esterification by diffuse reflectance fourier transform infrared spectroscopy. Food Chemistry, London, v.68, p.327-332, 2000.

HWANG, J. Purification and analysis of pectins. Journal of Korean Society of Food Science and Nutrition, Local, v.22, n.4, p.500-509, 1993.

INSTITUTO ADOLFO LUTZ. Normas analíticas do Instituto Adolfo Lutz. São Paulo: IAL,1985. v.1.

JOSHI, V. K.; KAUSHAL, N. K. Composition of apple pomace, standardization of pulp making, preparation and evaluation of apple pomace jam. Research and Industry, Stanford, v.40, n.3, p.203-207, 1995

KENNEDY, M.; LIST, D.; LU, Y.; FOO, L. Y.; NEWMAN, R. H.; SIMS, L. M.; BAIN, P. J.; HAMILTON, S. B.; FENTON, G. Apple pomace and products derived from apple pomace: uses, composition and analysis. Modern Methods of Plant Analysis, Berlin, v.20, p.75-119, 1999.

KERTESZ, Z. The pectic substances. New York: Interscience, 1951.p.528.
MANRIQUE, G. D.; LAJOLO, F. M. FT-IR spetroscopy as a tool for measuring degree of methyl esterification in pectins isolated from ripening papaya fruit. Postharvest Biology and Technology, Amsterdam, v.25, p.99-107, 2002.

MARCON, M. V.; VRIESMANN, L. C.; WOSIACKI, G.; BELESKI-CARNEIRO, E. Pectins from apple pomace. Polímeros: Ciência e Tecnologia, São Carlos, v.15, n.2, p.127-129, 2005.

MAY, C. D. Industrial pectins: sources, production and applications. Carbohydrate Polymers, Barking, v.12, p.7999, 1990.

MINKOV, S.; MINCHEV, A; PAEV, K. Modelling of the hydrolysis and extraction of apple pectin. Journal of Food Engineering, London, v.29, n.1, p.110-113, 1996.

NELSON, N. A photometric adaptation of the somogyi method for the determination of glucose. Journal of Biological Chemistry, Bethesda, v.153, p.375-380, 1944.

NOGUEIRA,A.;PAGANINI, C.; SILVA,N.C.C.; WOSIACKI, G. Aproveitamento de bagaço de maçã para a produção de álcool e obtenção de fibras alimentares. Ciência e Agrotecnologia, Lavras, v.29, n.6, p.179-186, 2005.

NOGUEIRA, A.; SANTOS, L. D.; PAGANINI, C.; WOSIACKI, G. Avaliação da fermentação alcoólica do extrato de bagaço de maçã. Semina: Ciências Agrárias, Londrina, v.26, n.2, p.179-186, 2005

PÉREZ, S.; MAZEAU, K.; PENHOAT, C. H. The threedimensional structures of the pectic polysaccharides. Plant Physiology and Biochemistry, Bethesda, v.38, n.1/ 2, p.37-55, jan./feb. 2000.

PILNIK, W. Pectin a many splendoured thing. In: PHILLIPS, G. O.; WILHAMS, P. A.; WEDLOCK, D. J. Gums and stabilizers for the food industry. Oxford: Oxford Press, 1990. p.313-326.

RENARD, M. G. C.; THIBAULT, J. F. Degradation of pectins in alkaline conditions: kinetics of demethylation. Carbohydrate Research, Bethesda, v.286, p.139-150, jun. 1996

ROLIN, C.; De VRIES, J. Pectin. In: HARRIS, P. Food Gels. London: Elsevier, 1990. p.401-434.

SCHEMIN, M. H. C. Obtenção de pectina alimentícia a partir de bagaço de maçã. 2003. Dissertação (Mestrado em Tecnologia de Alimentos)- Universidade Federal do Paraná, Curitiba.

SCHIEBER, A.; HILT, P.; STREKER, P.; ENDRESS, H. U.; RENTSCHLER, C.; CARLE, R. A new process for the combined recovery of pectin and phenolic compounds from apple pomace. Innovative Food Science and Emerging Technologies, Local, v.4, p.99-107, 2003. 
SOMOGYI, M. A new reagent for the determination of sugars Journal of Biological Chemistry, Bethesda, v.160, n.1, p.61-68, 1945.

TANNER, H.; BRUNNER, H. R. Getränke Analytic Untersuchungsmethoden für die Labor-und Betriebspraxis. Wädensvill: Verlag Heller, 1985.

THAKUR, B. R.; SINGH, R. K.; HANDA, A. K. Chemistry and uses of pectin - a review. Critical Reviews in Food Science and Nutrition, Boca Raton, v.37, n.1, p.47-73, 1997.

WANG, Q.; PAGAN, J.; SHI, J. Pectin from fruits. In: SHI, J.; MAZZA, G.; LE MAGUER, M.. Functional foods. Biochemical an processing aspects, Boca Raton: CRC Press, 2002
WILLATS, W .G. T.; KNOX, J. P.; MIKKELSEN, J. D. Pectin: new insights into an old polymer are starting to gel. Trends in Food Science and Technology, Cambridge, v.17, n.3, p.97-104, 2006

WOSIACKI, G.; KAMIKOGA, A. T. M.; CHIQUETTO, N. C.; ROCCO, C. S.; KIRCHNER, C. L. Estabilidade de sucos despectinizados de maçãs (safra 1988/1989). Boletim Centro de Pesquisa de Processamento de Alimentos, Curitiba, v.10, n.1, p.55-74, jan./jun. 1992. 